\title{
RESUSCITATION
}

\section{Out-of-hospital resuscitation in East Sussex: 1981 to 1989}

Susan J Lewis, S Holmberg, Elizabeth Quinn, K Baker, R Grainger, R Vincent, D A Chamberlain

\begin{abstract}
Objective-To assess the impact of extended training in advanced life support on the outcome of resuscitation. Design-Analysis of the successful resuscitations from 1981 to 1989.

Setting-Brighton and East Sussex.

Results-248 patients were resuscitated from cardiac or respiratory arrest in the community and subsequently survived to leave hospital. Their mean age was 64 years and one year survival was $77 \%$. In most cases the cause of collapse was cardiac but $38(15 \%)$ suffered a respiratory arrest. In 140 of the successful resuscitations (56\%) collapse occurred before the arrival of the ambulance. Basic life support, with ventilation and chest compression where necessary, was sufficient to revive 35 (14\%) of the patients. Defibrillation was also required in 107 patients (43\%), and in a further 106 patients $(43 \%)$ who had prolonged cardiorespiratory arrest requiring endotracheal intubation and the use of several drugs. Review of ambulance forms and case notes showed that in 87 cases (35\%) the abilities of the paramedical ambulance staff in advanced resuscitation techniques contributed decisively to the success of resuscitation. These skills are illustrated by eight case reports.

Conclusions-Extended training for ambulance staff increases the likelihood of successful resuscitation from out-ofhospital cardiopulmonary arrest. Though instruction in defibrillation must have the highest priority, full paramedical training can bring appreciable additional benefits.
\end{abstract}

(Br Heart f 1993;70:568-573)

Long-term success in resuscitation from sudden cardiac death can be achieved if intervention is both efficient and prompt. ${ }^{1-3}$ The policy of using only basic life support to sustain life during transport to hospital is rarely successful. Definitive treatment at the site of collapse is one of the major keys to success. ${ }^{4-6}$ In East Sussex, members of ambulance crews received hospital-based extended training in advanced life support techniques from 1971 until 1989. ${ }^{7-9}$ We have reviewed the results of intervention by the ambulance crews trained in Brighton from 1981 to 1989 . During this period training was more comprehensive than the programme introduced under the auspices of the National Health Services Training Authority (NHSTA) (now Training Directorate). ${ }^{10}$ We have attempted to assess the level of skills that influenced outcome in individual resuscitations. This may have implications for future training policies. The data collection and this review were undertaken before the Utstein style ${ }^{112}$ was described and for this reason the report is not fully compatible with the recommendations made for standardised reporting for out-of-hospital arrest.

\section{East Sussex Ambulance Service}

The East Sussex Ambulance Service is divided into East and West Divisions. This review is confined to the West Division which had a total of 42 ambulances: 27 in Brighton, eight in Hove, four in Lewes, and three in Newhaven. Thirteen of these 42 ambulances were fitted with defibrillation, suction, and intubation equipment during most of the period of our survey. They were known unofficially as "cardiac" ambulances but they had a wider remit in resuscitation. At the time the West Division had 120 ambulance staff. At any one time approximately a third of them had paramedical training.

The national ambulance service was set up with patient transport as its principal objective. It is not designated officially as an emergency service. Control policies that are designed for transport are not well suited for community resuscitation which therefore operates under important constraints. First, there was no separate rostering for paramedic ambulance staff who were therefore required to assist with routine transport duties. Though the general objective was always to assign a paramedic to a cardiac ambulance, this was often not achieved. Secondly, telephone messages to ambulance control often provide inadequate details ${ }^{13}$; if calls fail to specify collapse, chest pain, or severe breathlessness they may not be recognised as relating to cardiorespiratory emergencies so that fully equipped vehicles are not then dispatched. Thirdly, a resuscitation ambulance 
was not always available even if the significance of a message was clear. Finally, delays were also incurred because urgent calls outside the 999 system were dealt with by clerical officers and had to be relayed to trained staff. Whereas 999 calls have "immediate" priority, calls designated as "urgent" require a response within an hour. This crucial distinction was not always appreciated by general practitioners.

\section{PARAMEDIC TRAINING COURSE}

Training in paramedical skills in the East Sussex Ambulance Service started in January 1971. At that time there were no published reports of similar schemes from anywhere in the world. Instruction was designed to provide knowledge and skills that would enable ambulance crews, without the immediate advice of a doctor, to resuscitate patients from cardiac arrest and provide aid in medical emergencies.

The amount of medical instruction needed for this purpose was too great to be assimilated in a short course and accordingly a modular training programme was designed. The first module consisted of weekly lectures over six months to provide knowledge of the pathophysiology of heart disease and interpretation of the electrocardiogram (ECG), with instruction in resuscitation skills including defibrillation. The average failure rate was $25 \%$. The duration of the second module depended upon individual performance: each trainee was required to perform 25 successful endotracheal intubations under supervision in the operating theatre and to insert 25 intravenous cannulae. There was a third module for the intravenous administration of drugs. After the extended training, the members of the ambulance crew (now known informally as a paramedics) were required to spend a week in the hospital each year as a refresher course. In most cases the complete training period lasted about two years.

At the outset of the scheme drug treatment was restricted to the use of atropine and lignocaine during cardiac arrest, nitrous oxide and oxygen mixture for pain relief, and polygeline plasma expander for hypovolaemic shock. Subsequently other drugs were added to the list. These included adrenaline and glyceryl trinitrate spray, nebulised salbutamol for patients with acute asthma, glucagon for patients in hypoglycaemic coma, and naloxone for unconscious patients after drug overdose. All the drugs were chosen because of their wide margin of safety and the low probability of adverse effects even if administered incorrectly. Sodium bicarbonate was not included.

The structure of the course, as outlined above, did not change until the scheme for extended training was introduced by the National Health Services Training Authority (now Training Directorate). From 1989 onwards most extended training has been given independently from the hospital service and the results from this latter period are not included in our report.
METHODS

As part of a programme of continuing audit, detailed ambulance report forms were reviewed by our Research Sister (EQ) for all patients brought to the Royal Sussex County Hospital during the period of the study by a "cardiac" ambulance. Most were reviewed also by a consultant cardiologist.

Any ambulance forms that raised the possibility of a successful resuscitation were reviewed further in the light of the clinical case record, a supplementary report from the paramedic and, wherever possible, direct information from the patient and bystander(s).

Successful resuscitation was defined as discharge of a patient from hospital after a preadmission event that was judged likely to be fatal without treatment. Clinical events in this category were not defined rigidly, but included ventricular fibrillation, sustained pulseless ventricular tachycardia, persistent asystole, and prolonged apnoea. The hallmark of many cases was a new or "progressive" deterioration before intervention-that is, increasing exhaustion before collapse from severe asthma, dwindling cardiac output after trauma, worsening unconsciousness and respiratory function after drug overdose, increasing distress with airway obstruction, or a deteriorating malignant cardiac rhythm.

\section{FOLLOW UP}

A postal enquiry was sent to the general practitioner of each patient resuscitated, unless the patient had recently attended the hospital.

\section{Results}

PRE-HOSPITAL INTERVENTION

In the period 1981 to 1989 East Sussex ambulances (West Division) transported to hospital 163614 patients who had been classified as emergencies. Pre-hospital treatment was given by paramedics in 4818 cases during the period 1982 to 1989 (table 1). (Data for 1981 were incomplete and have been omitted from the table.)

\section{SUCCESSFUL RESUSCITATIONS}

From January 1981 to December 1989, 248 patients were successfully resuscitated from cardiac or respiratory arrest in the community and subsequently survived to leave hospital. Survivors were aged $21-92$ years (mean 64 years); 182 were male and 66 female. In most cases the cause was cardiac, but $38(15 \%)$ suffered a primary respiratory arrest (table 2). An automated external defibrillator-pacemaker was used in five of the successful resuscitations.

Over half the patients $(140(56 \%))$ had collapsed before the ambulance arrived and collapse was either the reason for the 999 call or occurred while the ambulance was travelling to the site. Bystanders, attending doctors, or relatives provided basic life support for 67 of these patients while the paramedics were awaited. In 108 cases (44\%) the collapse occurred after the arrival of the ambulance or 
Table 2 Successful resuscitations: cause of cardiorespiratory arrest

\begin{tabular}{lr} 
Cause & No \\
\hline Cardiac cause for & \\
collapse & 209 \\
Respiratory arrest: & 38 \\
Asthma & 8 \\
Chronic lung disease & 4 \\
Respiratory obstruction: \\
Choking & 3 \\
Angioneurotic & \\
$\quad$ oedema & 1 \\
$\quad$ Hanging & 1 \\
Pneumothorax & 1 \\
Pulmonary oedema & 2 \\
Drug overdose & 15 \\
Epilepsy & 1 \\
Head injury & 1 \\
Drowning & 1 \\
Hypovolaemia after & \\
stabbing & 1 \\
Total & 248 \\
\hline
\end{tabular}

in the vehicle on the way to hospital and thus was witnessed by the paramedics. In this group 19 patients with acute myocardial infarction were rapidly resuscitated from ventricular fibrillation without prolonged external chest compression, allowing them to receive intravenous thrombolytic therapy on arrival in hospital.

The first cardiac rhythm recorded by the paramedics after the collapse of the patients who were later successfully resuscitated was ventricular fibrillation in 169 cases (68\%), rapid ventricular tachycardia in 13 cases, asystole in 14 cases, sinus tachycardia or sinus rhythm in 18 cases (all respiratory arrests), sinus bradycardia in four cases, and a slow idioventricular rhythm in one case. In the remaining 29 cases (12\%) the cardiac rhythm was not recorded. In 14 of the 29 the cause of arrest was respiratory: provision of adequate ventilation resulted in revival of the patient with return of cardiac output. In another 14 patients there was good evidence of cardiac arrest: respirations and pulse were both absent but returned after external chest compression and artificial ventilation. In all of these, resuscitation had continued for sufficient time to make it extremely unlikely that the collapse was due to simple syncope. In one patient the rhythm could not be identified because of bright sunlight shining on the cardiac monitor. Ventricular fibrillation was suspected and the patient's pulse returned after a $200 \mathrm{~J}$ direct current shock.

A wide variation was seen in the extent of skills needed in resuscitation of the 248 patients. Basic life support was sufficient to resuscitate only 35 (14\%) of the 248 patients. Defibrillation with or without adjunctive drug therapy was sufficient in another 107 patients (43\%). The remaining 106 patients (43\%) had prolonged cardiorespiratory arrest with endotracheal intubation and the administration of several drugs. After careful review of the case reports we judged that in at least 87 cases $(35 \%)$ resuscitation would have been unlikely without advanced skills of the paramedics in addition to those of defibrillation.

FOLLOW-UP

Of 248 patients resuscitated over the nine year period 17 could no longer be traced; 179 of the remainder $(77 \%)$ were known to be alive at one year.

\section{Case reports}

The range of skills required by the paramedics is illustrated in a selection of case reports of successful resuscitations. (Details of other cases are available on request.)

A PRIMARY RESPIRATORY ARREST WTTH ASYSTOLE Mr A, aged 33, was attended by paramedics after an overdose of dextropropoxyphene, paracetamol, and vodka. When they arrived he was unconscious and unresponsive. Because of rapidly fading respiration $400 \mu \mathrm{g}$ of naloxone was given intravenously. At the same time cardiac output was lost and the monitor showed asystole. Chest compression was started and an endotracheal tube was passed. Adrenaline and atropine were given via the endotracheal tube; after several minutes a pulse became palpalable and the ECG showed sinus bradycardia. The patient started to breathe spontaneously soon after arrival in hospital. He was admitted to the intensive therapy unit and required artificial ventilation despite treatment with more naloxone and dexamethasone and an infusion of acetylcysteine. At first he had a spastic quadriparesis but he was eventually discharged physically well.

VENTRICULAR FIBRILLATION AND ASYSTOLE ON BOARD THE NUMBER ONE BUS

On 19 August 1982 an ambulance was called to $\mathrm{Mr} \mathrm{B}$, aged 48, who had collapsed on the Number One bus outside Hove Town Hall. He was deeply cyanosed, pulseless, and making no respiratory efforts. The other passengers and bus crew had not attempted any resuscitation. The paramedics started external chest compression. A DC shock $(200 \mathrm{D})$ was given after electrocandiographic confirmation of ventricular fibrillation. This resulted in asystole with $P$ waves. The patient was intubated with an endotracheal tube and ventilated. Ventricular fibrillation recurred and a second shock produced asystole, this time without any evidence of atrial activity. Asystole persisted and was unresponsive to external pacing. As a last resort, 10 $\mathrm{ml}$ of 1 in 10000 adrenaline was injected directly into the heart via the sub-xiphoid approach. A slow idioventricular rhythm appeared on the monitor but no pulse was palpable. After intravenous atropine the heart rate quickened with the return of a palpable pulse. On arrival in the accident and emergency department the patient had a good colour but the ECG showed evidence of recent inferior myocardial infarction. He was ventilated electively for 24 hours and thereafter made an excellent recovery.

RESUSCITATION AFTER HANGING

In June 1982 an ambulance crew were summoned to a flat in Hove. They were met by a woman who urged them to hurry because she thought that a 28 year old man was dead: he had been found hanging from a belt around his neck. They found him, already cut down, lying slumped in a lavatory. $\mathrm{He}$ was cyanosed but making only obstructed and ineffective respiratory efforts. A faint carotid pulse was palpable. There was no resistance when he was intubated with an endotracheal tube and ventilated with oxygen. His colour improved rapidly. During the journey to hospital he began to breathe spontaneously and made a full recovery over the next few days.

\section{A MARRIED COUPLE RESUSCITATED WITH THE} AUTOMATED EXTERNAI DEFIBRIILATOR-PACEMAKER In 1981 an automated external defibrillator-pacemaker was used to resuscitate both $\mathrm{Mr}$ and Mrs C who suffered cardiopulmonary arrest on separate occasions. Mr C, aged 72, who had a history of ischaemic heart disease, collapsed at home. His wife noticed that he was "shaking all over" and then he became blue and lifeless. She summoned an ambulance. The paramedics confirmed that the patient was apnoeic and pulseless. The oscilloscope showed coarse ventricular fibrillation and a shock of $320 \mathrm{~J}$ was given without further intervention from the paramedics. This resulted in an idioventricular rhythm which soon slowed to asystole. The patient was intubated with an endotracheal tube for a minute or two. Atrial fibrillation supervened. Intravenous lignocaine was administered. In hospital he was electively ventilated but later made an uncomplicated recovery with no evidence of myocardial infarction.

Two months later, Mrs C, aged 68, developed chest pain. After about half an hour she became very unwell and the general practitioner was called; she collapsed shortly after his arrival. He gave chest compression and mouth-to-mouth ventilation. The ambulance arrived and the patient was successfully defibrillated (two shocks) and then intubated. In hospital she suffered arrhythmias and a left hemiparesis, but eventual recovery was good. 
NEAR DEATH BY CHOKNNG

A resuscitation ambulance answered a call to go to restaurant in Brighton. They found Mrs D (who was 72) unconscious and apnoeic after choking, but still with a faint pulse. They attempted to perform the Heimlich manoeuvre but this was ineffective because the patient was overweight, unconscious, and sitting in a chair. Laryngoscopy showed bread and meat lodged in the larynx, and they were able to remove much of this using artery forceps. Once the airway had been cleared some spontaneous respiratory efforts returned. She was intubated to assist ventilation. Afte about 30 minutes the gag reflex returned and the tube was removed. She was discharged well on the following day.

CARDIAC ARREST ON BOARD SHIP

Ambulance control received a call to attend a patient with a "heart attack" on board a collier docked along side Shoreham power station. The ambulance arrived five minutes later. The captain had had some ches pain then collapsed at the dinner table. When the paramedics entered the mess, the captain was still sitting in a chair, but he was unconscious and apparently dead, with dilated pupils. The electrocardiogram confirmed residual ventricular fibrillation. A DC shock $(180 \mathrm{~J})$ resulted in an idioventricular rhythm, and then sinus bradycardia. After endotracheal intubation the cardiac rhythm very quickly became sinus tachycardia the pupil size reduced, and spontaneous respirations returned. Lignocaine was given intravenously. His condition stabilised after some brief convulsions. Elective ventilation was continued for 24 hours and progress thereafter was quite uncomplicated. The patient suffered some initial loss of memory, but within a day or two he was fully orientated and soon returned home.

COLLAPSE OF A POP STAR

$\mathrm{Mr} \mathrm{E}$ aged 21, was travelling with his friends in a van. He started to look unwell and complained of chest pain. His friends stopped outside a doctor's surgery. They carried him in and requested an urgent consultation. Within a short time $\mathbf{M r} \mathbf{E}$ vomited and stopped breathing. The general practitioner started cardiopulmonary resuscitation and called for a resuscitation ambulance. The paramedics noted asystole on the cardiac monitor. They intubated the patient and inserted an intravenous cannula while the genera practitioner continued external chest compression. Intravenous adrenaline $(10 \mathrm{ml}$ of 1 in 10000$)$ resulted in ventricular fibrillation. After a DC shock (180 J) asystole recurred. After further external chest compression a broad complex bradycardia was seen on the monitor but no pulse was palpable. A cycle of further ventricular fibrillation, cardioversion, and asystole recurred until sinus bradycardia supervened, interspersed with a brief salvo of ventricular tachycardia Stability was eventually achieved after doses of atropine and lignocaine and further defibrillation. The cardiac resuscitation in the surgery lasted 26 minutes in all. $\mathrm{Mr} \mathrm{E}$ was then transported to hospital. He was electively ventilated for $\mathbf{4 8}$ hours. A few days after he had been weaned from the ventilator, he was transferred to a cardiac centre for investigation.

CARDIAC ARREST AT GLYNDEBOURNE

In October 1987, Mrs F, aged 49 years, attended the opera at Glyndebourne with her husband. She had suffered from palpitation since childhood. At the end of the evening's entertainment Mrs F noticed her usual palpitation and felt short of breath. Within a few seconds she had collapsed and was unconscious with a poor colour. Mr F was alarmed and laid her on a flat surface but did not attempt resuscitation. An announcement was made to call for a doctor. An oral surgeon and a registrar in anaesthetics arrived and found the patient to be cyanosed and pulseless with dilated pupils. Chest compression and mouth to mouth ventilation were started. The ambulance from Lewes was delayed by the traffic leaving through the narrow lanes around Glyndebourne, but after considerable delay an ECG monitor showed ventricular fibrillation. A DC shock (200 J) was ineffective, but the second shock resulted in "rapid ventricular tachycardia" with no cardiac output. The patient was intubated and ventilated. After lignocaine, given down the endotracheal tube, and two further shocks a supraventricular tachycardia supervened and the pulse became palpable. The patient was moved to the ambulance. One further DC shock was required in the ambulance, but thereafter the journey to the hospital was uneventful. Mrs F made a good recovery and was transferred to a cardiac centre.

\section{Discussion}

Sudden cardiac death can be reversed only by prompt institution of a series of interventions. These form the links of the "chain of survival". ${ }^{14}$ The American Heart Association has recently emphasised the essential components of this chain. ${ }^{15}$ These are early access to emergency medical services, early cardiopulmonary resuscitation, early defibrillation, and early advanced cardiac care.

Early access to emergency medical services, the first component, requires immediate recognition of a life-threatening emergency followed by rapid contact with the appropriate emergency service. The quality of information given is unfortunately often inadequate. ${ }^{12}$

The second component in the chain of survival is cardiopulmonary resuscitation. Several studies have shown that immediate basic life support increases the likelihood of a successful outcome. ${ }^{1617}$ Those present to witness the cardiac arrest are usually relatives of the patient or bystanders who have had no formal medical training. Their knowledge of external cardiac compression and mouth-tomouth ventilation depends upon community training schemes in resuscitation. Our series is unusual in that over $50 \%$ of survivors of sudden cardiac death (140 patients) collapsed before the arrival of the ambulance. The impressive number of successes after relatively long delay may have been due in part to the use of basic life support. But only 67 of the 140 patients $(48 \%$ ) had the benefit of cardiopulmonary resuscitation from bystanders. We do not doubt that the advanced skills of the paramedics saved many patients, though some may have had ventricular tachycardia with some cardiac output before progressing to cardiac arrest. Greater nationwide availability of community training schemes would facilitate the rapid recognition of sudden cardiac death and the more widespread use of cardiopulmonary resuscitation, and hence increase survival rates from aborted sudden cardiac death. ${ }^{18} 19$

Early defibrillation, the third component, is of paramount importance. ${ }^{1020}$ Ventricular fibrillation is the most common arrhythmia of cardiac arrest. A recent study of sudden cardiac deaths recorded by ambulatory monitoring showed this rhythm in $83 \%$ of cases. $^{21}$ The best method of bringing the defibrillator and operator to the patient depends on the situation and circumstances. 
One approach has been to issue defibrillators to general practitioners ${ }^{22}$ or place them in strategic sites such as railway stations and football stadia. ${ }^{23}$ Though this is helpful, only a small proportion of cardiac arrests occur in the presence of a general practitioner or in such densely crowded public areas: most occur in the home. ${ }^{15}$

It is now widely accepted that defibrillation can be safely performed by trained nonmedical personnel and that all "first responders" should be provided with defibrillators. The defibrillators may be manual, as generally used by the highly trained Brighton paramedics, or automated external defibrillators, which are suitable for less experienced operators. The National Health Services Training Directorate have recently recommended that from 1995 every front line ambulance in England and Wales should be staffed by one paramedic and one technician and should be fitted with a defibrillator. As an interim measure until the training targets can be achieved an external automated defibrillator is to be placed in every front line vehicle. ${ }^{10}$

The fourth component in the chain of survival is early advanced cardiac care. Some have advocated that the ambulance crew's role should be limited to basic life support and defibrillation. ${ }^{24-26}$ When this is unsuccessful the patient is brought to hospital for advanced cardiac care. But patient survival rates with this approach have been disappointing. ${ }^{27}$ Another option is to bring advanced cardiac care to the patient using the "coronary ambulance" staffed by doctors and nurses. ${ }^{28}$ Several studies have shown that this can be highly successful in achieving on site resuscitation including advanced life support. ${ }^{1729}$ But the high cost in manpower and the delay in despatch introduced by the requirement for a doctor have made these excellent schemes impractical in most parts of the United Kingdom. ${ }^{30} 31$

In Brighton efficient advanced cardiac care has been provided by the paramedics since 1971. A review of the successful resuscitations of the last nine years shows the advantages of this approach. We accept that, on occasion, it can be difficult to be sure that the recovery of a collapsed patient depended on treatment rather than a spontaneous improvement. But from a careful scrutiny of hospital and pre-hospital records together with supplementary information, we believe at least $35 \%$ of the 248 successful resuscitations would have been unlikely if advanced life support facilities and skills had not been immediately available. Though short training courses in defibrillation and basic life support will achieve much, extended training of selected ambulance crew men and women can bring added benefits. The availability in recent years of extended training is a welcome development. ${ }^{10}$

\section{Summary}

Members of ambulance crews in East Sussex received local instruction in advanced life support from 1971 until 1989 when extended training was introduced through the National Health Service Training Authority. The resuscitations of 1981 to 1989 have been reviewed: 248 of the patients survived to leave hospital. In 140 (56\%) of the successful resuscitations, collapse had occurred before the arrival of the ambulance. Basic life support alone was sufficient to revive 35 (14\%) of the 248 patients. Rapid defibrillation, sometimes with adjunctive drug therapy, was successful in 107 patients (43\%). But 106 patients $(43 \%)$ survived only after prolonged resuscitation involving endotracheal intubation and the use of several drugs. Evaluation of the case reports suggested that the advanced skills of the East Sussex paramedic ambulance crew members were decisive in the survival of 87 (35\%) of the resuscitated patients. The recent inclusion of defibrillation skills in the standard (Miller) training of ambulance crews is a major advance but comprehensive training to paramedic status can bring appreciable additional benefits.

1 Eisenberg MS, Hallstrom A, Bergner L. Long-term survival after out-of-hospital cardiac arrest. $N$ Engl $\mathcal{F} \mathrm{Med}$ 1982;306:1340-3.

2 Ritter G, Wolfe RA, Goldstein S, et al. The effect of bystander CPR on survival of out-of-hospital cardiac arrest victims. Am Heart f 1985;110:932-7.

3 Weaver WD, Cobb LA, Hallstron AP, Fahrenbruch C Copass $M K$, Ray $R$. Factors influencing survival after Out-of 7:752-7.

4 Jaggarao NSV, Heber $M$, Grainger $R$, Vincent $R$ Chamberlain DA. Use of an automated external defibrillator-pacemaker by ambulance staff. Lancet 1982; rillator-pace

5 Cobbe SM, Redmond MJ, Watson JM, Hollingworth J, Carrington DJ. "Heartstart Scotland"-initial experience of a national training scheme for out of hospital defibrillation. BrMed f 1991;302:1517-20.

6 Cummins RO. From concept to standard-of-care? Review of the clinical experience with automated exter nal defibrillators. Ann Emerg Med 1989;18:1269-75.

7 White NM, Parker WS, Binning RA, Kimber ER, Ead HW, Chamberlain DA. Mobile coronary care provided by ambulance personnel. Br Med f 1973;iii:618-22.

8 Briggs RS, Brown PM, Crabb ME, et al. The Brighton resuscitation ambulances: a continuing experiment in ii: $1161-5$.

9 Mackintosh AF, Crabb ME, Grainger R, Williams JH, Chamberlain DA. The Brighton resuscitation ambulances: review of 40 consecutive survivors of out-ofhospital cardiac arrest. Br Med f 1978;i:1 $115-8$.

10 National Health Service Training Directorate. National Health Service Training Manual. Swindon Press, 1991.

11 Recommended guidelines for uniform reporting of data from out-of-hospital cardiac arrest: the "Utstein style". from out-of-hospital cardiac arrest: the "Utstein style".
Prepared by a task force of representatives from the European Resuscitation Council, American Hear Association, Heart and Stroke Foundation of Canada, Australian Resuscitation Council. Resuscitation 1991, 22:1-26.

12 Recommended guidelines for uniform reporting of data from out-of-hospital cardiac arrest (new abridged version), the "Utstein style". Prepared by a task force of Council, American Heart Association, Heart and Stroke Foundation of Canada, and Australian Resuscitation Council. Br Heart $\mathcal{F}$ 1992;67:325-33.

13 Rowley JM, Garner C, Hampton JR. The limited potential of special ambulance services in the management of cardiac arrest. Br Heart $f$ 1990:64:309-12.

14 Ahnefeld FW. Die Vorbereitungen fur den Katastrophenfall aus arzlicher Sicht. Med Hyg 1966:24:1084-8.

5 Cummins RO, Omnto IP, Thies WH, Pepe PE. Improving survival from sudden cardiac arest: the "mproving survival from sudden cardiac arrest: the chain of survival" concept. A statement for health professionals from the Advanced Cardiac Life Support Subcommittee and the Emergency Cardiac Care Committee, Am

16 Thompson RG, Hallstrom AP, Cobb LA. Bystanderinitiated cardiopulmonary resuscitation in the management of ventricular fibrillation. Ann Intern Med 1979; 90:737-40. 
17 Bossaert L, Van Hoeyweghen R, Cerebral Resuscitation Study Group. Bystander cardiopulmonary resuscitation (CPR) in out-of-hospital cardiac arrest Resuscitation 1989;17(suppl):55-69, 199-206.

18 Vincent R, Martin B, Williams G, Quinn E, Ruberbon G, Chamberlain DA. A community training scheme in cardiopulmonary resuscitation. $\mathrm{Br}$ Med $\mathcal{F}$ 1984:288;617-20.

19 Raffle PAB, ed. Mass education in emergency aid: a report on the save-a-life campaign. London: Royal Society of Medicine, 1989.

20 Wright D, Bannister J, Ryder M, Mackintosh AF. Resuscitation of patients with cardiac arrest by ambulance staff with extended training in West Yorkshire. $B$ Med F 1990;301:600-2.

21 Bayes de Luna A, Coumel P, Leclercq JF. Ambulatory sudden cardiac death: Mechanisms of production of fatal arrhythmia on the basis of data from 157 cases. $\mathrm{Am}$ Heart $¥ 1989 ; 117: 151-9$.

22 Colquhoun MC. Use of defibrillators by general practitioners. Br Med F 1988;297:336.

23 Jaggarao NSV, Sless H, Grainger $R$, Vincent $R$, Chamberlain DA. Defibrillation at a football stadium: an experiment with Brighton and Hove Albion. $\mathrm{Br} \mathrm{Med}$

24 Stults KR, Brown DD, Schug VL, Bean JA. Prehospital defibrillation performed by emergency medical technicians in rural communities. $N$ Engl $f$ Med 1984 310: 219-23.

25 Rowley JM, Mounser P, Garner C, Hampton JR Advanced training for ambulance crews: implication from 403 consecutive patients with cardiac arres managed by crews with simple training. $\mathrm{Br} \mathrm{Med}$ 1987;295:1387-90.

26 Anderson IWR, Black RJ, Ledingham I McA, Little $K$ Robertson. CE, Urquhart ID. Early emergency care study: the potential and benefits of advanced prehospital care. Br Med F 1987;294:228-31.

27 Jakobsson J, Rehnqvist N, Nyquist $O$. One year's experience of early defibrillation in Stockholm. $\mathcal{F}$ Intern Med 1989;225:297-301.

28 Pantridge JF, Geddes JS. A mobile intensive-care unit in the management of myocardial infarction. Lancet 1967 ii:271-5.

29 Dickey W, MacKenzie G, Adgey AAJ. Long-term survival after resuscitation from ventricular fibrillation occurring before hospital admission. $O F M$ Med 1991;80:729-37.

30 Hampton JR, Dowling M. Nicholas C. Comparison of results from a cardiac ambulance manned by medical or non-medical personnel. Lancet 1977;1.526-9.

31 Hampton JR, Nicholas C. Randomised trial of a mobile coronary care unit for emergency calls. $\mathrm{Br} \mathrm{Med} \mathcal{F} 1978$ 1:1118-21.

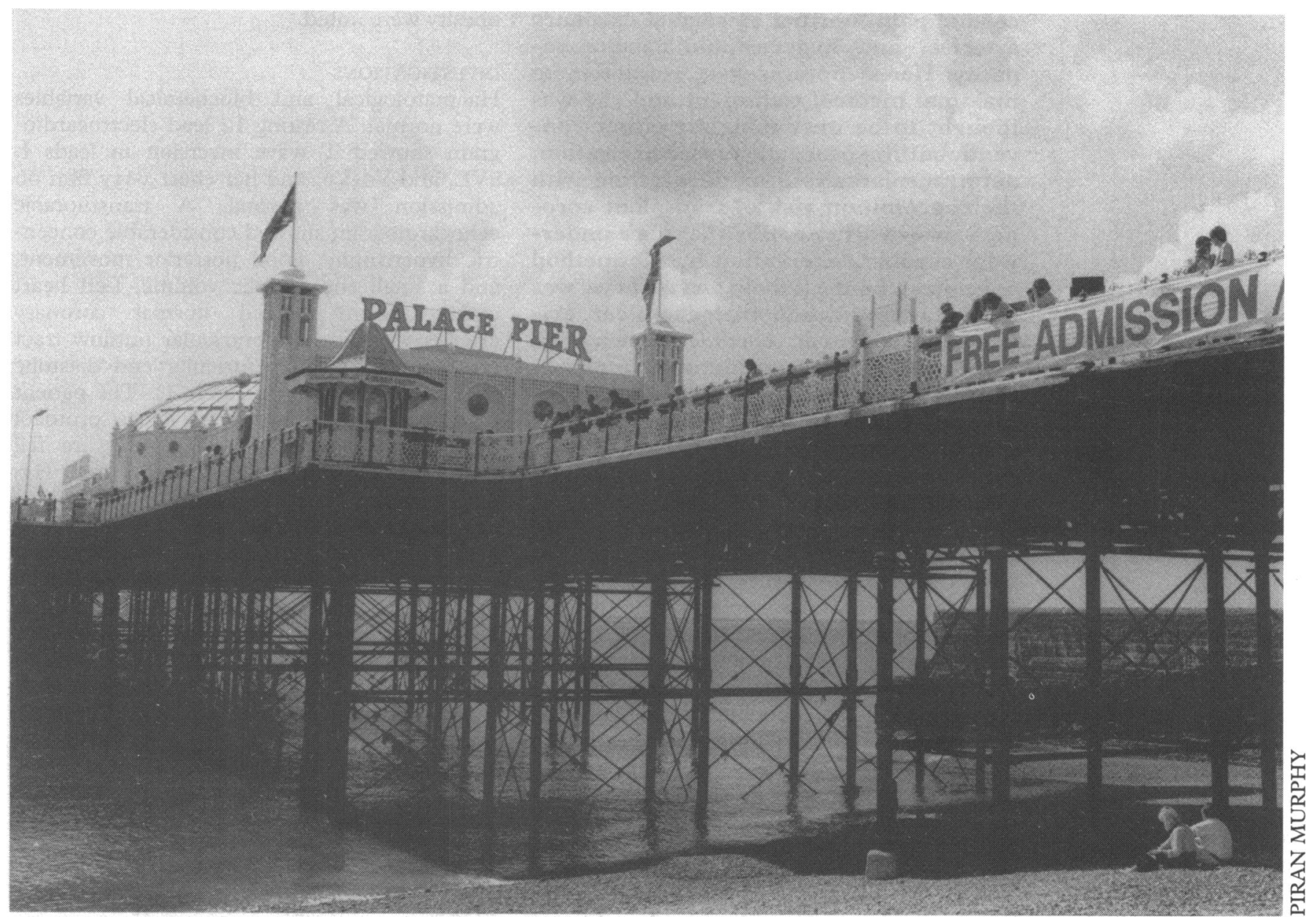

